\title{
LdShake: Learning design solutions sharing and co-edition
}

\author{
Davinia Hernández-Leo a, ${ }^{\text {, }}$ Lauren Romeo ${ }^{a}$, Miguel A. Carraleroa, Jonathan Chacón ${ }^{\mathrm{a}}$, Mar Carriób, Pau \\ Morenoa, Josep Blata \\ aDepartment of Information and Communication Technologies, Universitat Pompeu Fabra, Roc Boronat 08018 Barcelona, Spain \\ bDepartment of Experimental and Health Sciences, Universitat Pompeu Fabra, Dr. Aiguader 88, 08003, Barcelona, Spain
}

\author{
${ }^{*}$ Corresponding author. Tel.: + 34 935421428; Fax: + 34935422517 \\ E-mail address: davinia.hernandez@upf.edu (D. Hernández-Leo)
}

\begin{abstract}
Two important challenges that teachers are currently facing are the sharing and the collaborative authoring of their learning design solutions, such as didactical units and learning materials. On the one hand, there are tools that can be used for the creation of design solutions and only some of them facilitate the co-edition. However, they do not incorporate mechanisms that support the sharing of the designs between teachers. On the other hand, there are tools that serve as repositories of educational resources but they do not enable the authoring of the designs. In this paper we present LdShake, a web tool whose novelty is focused on the combined support for the social sharing and co-edition of learning design solutions within communities of teachers. Teachers can create and share learning designs with other teachers using different access rights so that they can read, comment or co-edit the designs. Therefore, each design solution is associated to a group of teachers able to work on its definition, and another group that can only see the design. The tool is generic in that it allows the creation of designs based on any pedagogical approach. However, it can be particularized in instances providing pre-formatted designs structured according to a specific didactic method (such as Problem-Based Learning, PBL). A particularized LdShake instance has been used in the context of Human Biology studies where teams of teachers are required to work together in the design of PBL solutions. A controlled user study, that compares the use of a generic LdShake and a Moodle system, configured to enable the creation and sharing of designs, has been also carried out. The combined results of the real and controlled studies show that the social structure, and the commenting, co-edition and publishing features of LdShake provide a useful, effective and usable approach for facilitating teachers' teamwork.
\end{abstract}

Keywords:

Authoring tools and methods; Computer-mediated communication; Human-computer interface; Media in education. 


\section{Introduction}

The design of problems is crucial for the effectiveness of the Problem-Based Learning methodology (PBL) (Barrows, 2002). This principle is very present in the Human Biology degree of Pompeu Fabra University. Its curriculum includes a set of so-called "integrated courses" based on problems whose resolutions require the knowledge of different biomedical disciplines coursed by the students in previous subjects (Carrió, Larramona, Baños, \& Pérez, in press). The main challenge around the preparation of the courses is managing the collaborative authoring of the interdisciplinary problems by teams of teachers with different backgrounds (i.e. experts in the previous subjects), such as Evolution, Biochemistry, Anatomy, Physiology, Statistics, etc. The coordinator of the integrated courses would ideally like that all of the teachers involved in the creation of problems for the courses are aware of each problem considered, so that the resulting collection of problems is complementary; and those teachers expected to contribute to a problem have the rights to co-edit them.

Designing high quality designs is a significant concern for educators and their institutions, not only in PBL but, generally, in any pedagogical approach (Lockyer, Bennett, Agostinho, \& Harper, 2008). As in the previously described scenario, two main challenges have been identified in the literature to cope with this concern. The first challenge is focused on fostering the cooperation between educators in teams where they can actively participative in the collaborative co-creation of designs (Cifuentes, Sharp, Bulu, Benz, \& Stough, 2009; Dodero et al., 2007; Koper \& Tattersall, 2004). The second challenge is centred on facilitating the sharing of relevant designs so that other educators can reuse them in their own educational settings (Hernández-Leo, Harrer, Dodero, Asensio-Pérez, \& Burgos, 2007; Wichmann, Engler, \& Hoppe, 2010).

A number of tools have been developed to support the creation of educational designs, however they only provide partial solutions to the challenges described above. Editors compliant with educational technology standards such as SCORM or IMS Learning Design (IMS LD) have been implemented providing a common format for the designs and enabling interoperability (González-Barbone \& Anido-Rifón, 2010; Koper \& Olivier, 2004). However, these editors do not incorporate explicit co-authoring support and facilitate only to a limited extent the reuse of sound designs (Neumann et al., 2010). There are a significant number of approaches that propose authoring tools supporting collaborative writing and demonstrating how they improve teams' coordination, productivity and quality of the results (Calvo, O'Rourke, Jones, Yacef, \& Reimann, 2011; Lorry \& Nunamaker, 2003; Neuwirth, Kaufer, Chandhok, \& Morris, 1990; Strobel, Jonassen, \& Ionas, 2008). Nevertheless, these co-editors are not specifically focused on the teachercentred authoring of learning designs and do not incorporate devoted social network features for the sharing of the designs within communities of practitioners. On the other hand, several projects and initiatives have tackled the sharing of educational resources from different perspectives, always separately from the co-authoring problem.

Glow (2011) and Agrega (Sarasa, Canabal, \& Sacristán, 2009) are two important large-scale digital repositories devoted to promoting the sharing and reuse of educational resources. Besides, there are approaches focused on supporting the sharing of learning designs, which go beyond educational content and include the definition of activities. The AUTC and the Phoebe project (2011) established portals to gather learning designs resulting from the projects. LAMS (2011) has also made available a central repository that facilitates the sharing of LAMS sequences. Elferink, Griffiths, \& Veenendaa (2006) developed a distributed repository specifically dedicated to activities compliant with IMS LD. Except from some successful institutional-scale initiatives such as OpenLearn (McAndrew et al., 2008) or the OpenCourseWare (Abelson, 2008), the take-up of large-scale open repositories is small since educators have shown to rarely share resources and continuous investment is required to populate and maintain the sites (Davis et al., 2010). Besides, educators have shown to share more resources in closer communities, when they want to preserve and control the ownership of their materials, or when they are not sufficiently confident in aspects of their designs, or when the institutional preferred practice is to keep the resources locked into the institution learning management system (Davis et al., 2010; RIN, 2008). This is the reason why educational centres or emergent teams of teachers often decide to use management systems (e.g., Moodle) that are already available in their institutions to build a space for educators' cooperation (Dodero et al., 2007). Interestingly, recent initiatives adopt the key principles of well-known Web2.0 tools that encourage people to share and reuse their resources by explicitly supporting social networking among educators and by presenting the designs as social objects that facilitate conversation. Relevant tools in this line are Cloudworks (Conole et al., 2008) and EdShare (Davis et al., 2010). The observed usage of these Web2.0-based approaches is encouraging and, as the previous platforms, they are all relevant products supporting the sharing challenge. However, they do not present facilities for the collaborative creation of the designs.

This paper presents the LdShake tool as an approach that faces the two challenges, sharing learning designs and cooperation between teachers in the creation of new solutions. The novelty of the proposal 
relies on the combination of features adopted from the areas of co-authoring support, small communities repositories and social network platforms. LdShake supports the creation of learning design solutions based on any pedagogical approach. However, particularized versions of the system can be instantiated so as to provide design structures formatted according to specific didactic methods. Section 2 describes LdShake explaining the decisions adopted in its design and its technical implementation. Then, section 3 is devoted to explain how LdShake is being used in the real case study of integrated courses of the mentioned Human Biology degree and the results of a controlled user study in which LdShake has been compared with the Moodle management system. The contrasted analysis of the lessons learned in the real scenario and the findings obtained in the controlled study provides a meaningful evaluation of the usefulness and usability of LdShake. Finally, section 4 is devoted to present the conclusions of the paper and the derived future work.

\section{The LdShake tool}

LdShake is a web tool for the social sharing and co-edition of learning design solutions. The name "LdShake" stands for "Learning design solutions - Sharing and (k)co-edition" and uses the "shake" metaphor to emphasize that the tool aims at facilitating teachers to shake their hands with other educators in their social network by collaborating with them in the co-edition of joint learning design solutions, to shake their way of working by sharing designs with other teachers, and to shake different learning design solutions shared by others to elaborate new designs in order to shake the students (see Welcome page for LdShake logged users in Fig. 1).

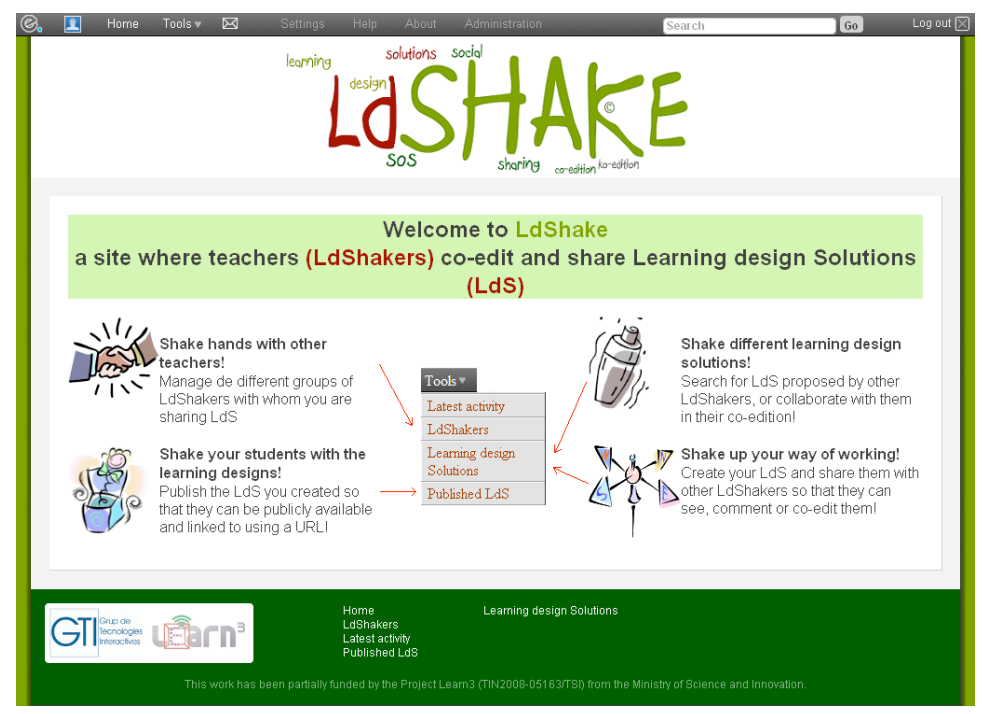

Fig. 1. Welcome page to LdShake. (LdShake is available online at http://ldshake.upf.edu/ldshake)

Teachers or learning designers registered in LdShake, who are referred to as LdShakers, can create and edit different types of educational materials and activities (Lockyer et al., 2008) that are generally termed as Learning design Solutions ( $L d S$ ). Though future plans include enabling the creation of standardcompliant learning designs, such as IMS LD, the current version of LdShake allows authoring LdS whose body is a collection of HTML documents, so that they can be enriched with any kind of embeddable multimedia element present in the Internet. An LdS consists also of some open metadata and parameters that describe it and define its usage, such as description tags, an indicator of how ready it is for classroom use (fullfledged resource vs. refinable template, Hernández-Leo et al., 2007), or its sharing options.

LdShake implements read/write Web technologies, as they have been proved to address the problems of co-user-authored content in communities of teachers (Cifuentes et al., 2009), and combines them with commenting support (Neuwirth, Kaufer, Chandhok, \& Morris, 1990). LdShake sharing options allow granting access rights to the LdS so that pointed LdShakers can be readers or co-editors of such LdS. Readers can read and add comments to an LdS, while co-editors can also modify or extend the LdS. In this way, the LdS acts a shared social object (Knorr-Cetina, 1997) that connects an educator with other LdShakers, creating automatically and transparently their social network. Users can also create named collections of LdShakers (e.g., "Biology teachers"), which are visible just for them, and share their LdS directly with the members of these collections. With this functionality the platform facilitates group work, as sharing an LdS with a group is a matter of selecting the group name in the LdS options. A group can be also modified and subsequently the access permissions of all of the LdS shared with this group are 
automatically updated. Therefore, each LdS has associated a team of LdShakers able of working on its authoring, and a group of LdShakers that can only see the design solution. These teams of LdShakers can be also "all logged in users". The creator of the LdS acts as the coordinator and manager of the LdS lifecycle, including the definition (and change) of its sharing rights and the number of HTML documents it comprises.

The discoverability of LdS is supported with an approach based on simple user generated tagging. This mixture of folksonomy and provision of structure together with the use of clear terms that relate to the teaching practice seems to be an appropriate approach in Web2.0 platforms where educators are the endusers (Conole et al., 2008; Davis et al., 2010; Lockyer et al., 2008). In LdShake, the metadata associated to each LdS is generated from the title, its description, the discipline and the pedagogical approach tags. Apart from a search engine, LdShake offers two LdS discovery tools in the shape of three-dimensional tag clouds. The first cloud renders the aforementioned LdS generated tags. By exploring the cloud, a user can easily see what designs can be found (by her/him, depending on the access rights) in the platform and the most common topics addressed by the LdS shared in the platform. The second cloud visualizes the network of LdShakers sharing LdS with the user so that s/he can directly access the designs created by each of them.

In the LdS section of the site, the users will find three different listings of their social objects: Their own LdS (those created by them), the designs that they can edit, and all the LdS they can view (see Fig. 2). While the first two listings act as a shared and remote file system for LdS, the last listing acts as a repository viewer. As it is typically supported in co-authoring editors, such as wikis (Cifuentes et al., 2009), along the text of an LdS users can navigate through a revision history of its contents, seeing who has made each modification and when has made it.

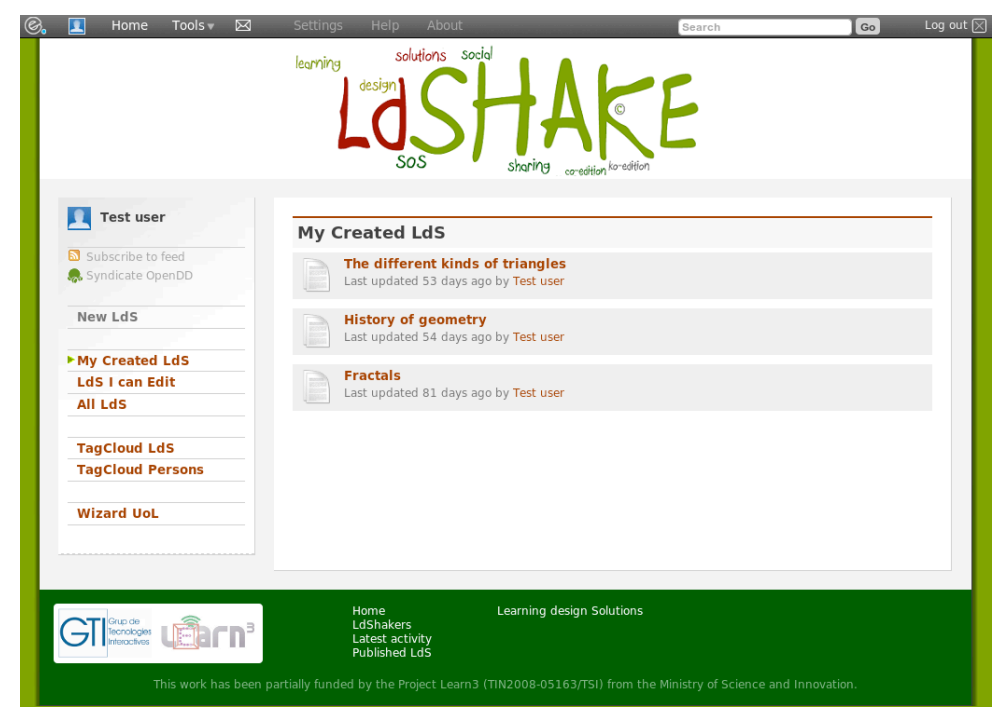

Fig. 2. LdS organized into "My Created LdS", "LdS I can Edit”, “All LdS”, and in tag clouds.

Given the myriad of course management systems that exist nowadays, it was seen as useful to be able to (openly) publish a ready LdS through a unique URL, which can be easily referenced or linked anywhere (e.g., the learning management system that is used by the students). The creator of an LdS can publish it, and its associated public URL becomes visible for all the LdShakers that can read the LdS. Having this URL, any user, even those not logged into the system, can view the LdS (though they cannot comment it). The owner of the LdS can later decide to unpublish the LdS in order to make it no longer available out of LdShake.

LdShake is built on top of the Elgg platform. Elgg is an open source social networking engine written in PHP (Sharma, 2008). It offers a comprehensive set of functionalities for social network sites, ranging from contact management tools to an internal messaging module. Internally, Elgg treats all the information published in the site as entities with associated metadata. By having this data homogeneity, Elgg-based sites are very easily enhanced, as adding new modules to them does not require extra coding. There is a numerous community of contributors behind Elgg, who are frequently releasing new modules, as well as updating the engine's core. The counterpart of this modularity is that having such a generic data model goes at the expense of scalability, but Elgg has been seen as a good option for a rapid building of ready-touse social networking tools such as LdShake.

LdShake re-uses an existing module to create wikis in the platform to implement all the core LdSrelated functionalities. However, other functionalities such as tag clouds, importing and exporting tools and LdShake-specific LdS management are located in independent modules that can be activated or 
disabled from a site administrator control panel. The idea behind this architecture is that it must be easy to personalize LdShake according to the specific requirements of a particular group of users. LdShake is built as a generic tool that can be used for the creation of any learning design type. However, it can be also customized according to the needs of institutions or teaching units using specific didactic methods. This is for example the situation of the scenario we described at the beginning of the paper, where in the Human Biology studies at UPF, PBL is used as the pedagogical method and all the LdS should follow a common predefined structure.

\section{Application case and controlled user study}

To evaluate the value of LdShake for addressing the challenges pointed out in the introduction, this section explains how LdShake is being used in the real case study of integrated courses of the Human Biology degree. For this case, LdShake was particularized into an instance that provided LdS formatted according to the PBL methodology. Moreover, this section includes a controlled user study in which a number of teachers used the generic version of LdShake and a control system (Moodle) to fulfil a set of tasks that are representative of the identified challenges. The contrasted and aggregated analysis of the conclusions achieved in both settings shapes a discussion of the global usefulness and usability of LdShake.

\subsection{Implementation in Integrated Biomedicine courses}

In the 2008-2009 academic year, the curriculum for the Human Biology degree in the Faculty of Health and Life Sciences of Pompeu Fabra University was revised according to the guidelines of the European Higher Education Area (EHEA, Lloret, \& Mir, 2006). One of the aims for the new curriculum was to offer a framework allowing the integration of the knowledge and skills developed by the students in several subjects that they had previously coursed as well as the development of transversal or general skills, such as group work. To achieve this aim the new curriculum included the so-called "Integrated Biomedicine" courses in the first three years (out of four) of the degree: Integrated Biomedicine I, II and III (BMI-I, II and III). The courses were based on the Problem-Based Learning (PBL) methodology (Carrió et al., 2011) and their credits are equivalent to the other subjects of the degree (100 hours dedication, in and out of the classroom). Every course was structured around 4 problems, which were approached in groups of 8-10 students and a tutor. From 2008 to 2011, BMI-I, II and III are being consecutively implemented.

As mentioned in the introduction, the PBL literature shows that problem design is one of the key aspects for the success of the methodology. In PBL, problems are contextualised situations, scenarios or cases that need to be clarified. They do not have a unique solution and trigger the learning of different knowledge areas. BMI-I, II and III use ill-structured problems containing students' professional future elements, as it has been demonstrated to be more effective (Barrows, 2002). One of the main challenges of the integrated courses was to create teams of teachers able to design effective interdisciplinary problems. In this way, a team of six teachers from different areas of expertise (Evolutionary Biology, Biochemistry, Anatomy, Physiology, Physics, etc.) were in charge of each course, one of them being the coordinator. All of the teachers were expected to be involved in the design of the problems and to participate as tutors of the students groups. Moreover, to ensure coordination between problems and courses, it was also desired that all the teachers involved in the BMI-I, II and III courses were aware of the problems being addressed in the other (two) courses.

In previous shorter-scale pilot experiences using PBL with interdisciplinary problems in the Human Biology degree, the coordinator of the pilot reported a number of problems derived from using the e-mail as the tool to support the collaborative creation of the problems. These difficulties were related to the organized sharing of the problems (taking into account who must edit, who should also send comments, etc.), the management (or control) of the document revisions performed in parallel by the different teachers, the discussion around the comments, and the coordinator's workload. In this context, LdShake appeared to be the tool able to tackle these problems.

The LdShake tool was adapted according to the needs of this specific context. Because the learning design solutions in this case were all to be based upon the PBL methodology, the body of the LdS was customized in order to serve as a template for the creation of these specific problems. Each problembased LdS had by default three sections: one for the "problem scenario", another for the "learning objectives" and the third one for the "tutor's guide" (see Fig. 3). Moreover, a fourth section "following up" was associated to the LdS. This section was devoted to share the experience and suggestions of the tutors as observed during the course deployment. From that moment, LdShake has been used for the collaborative creation of the eight problems required for BMI-I and II (four problems/course) and will continue to be used in the 2011-12 academic year for the creation of the problems for BMI-III. 


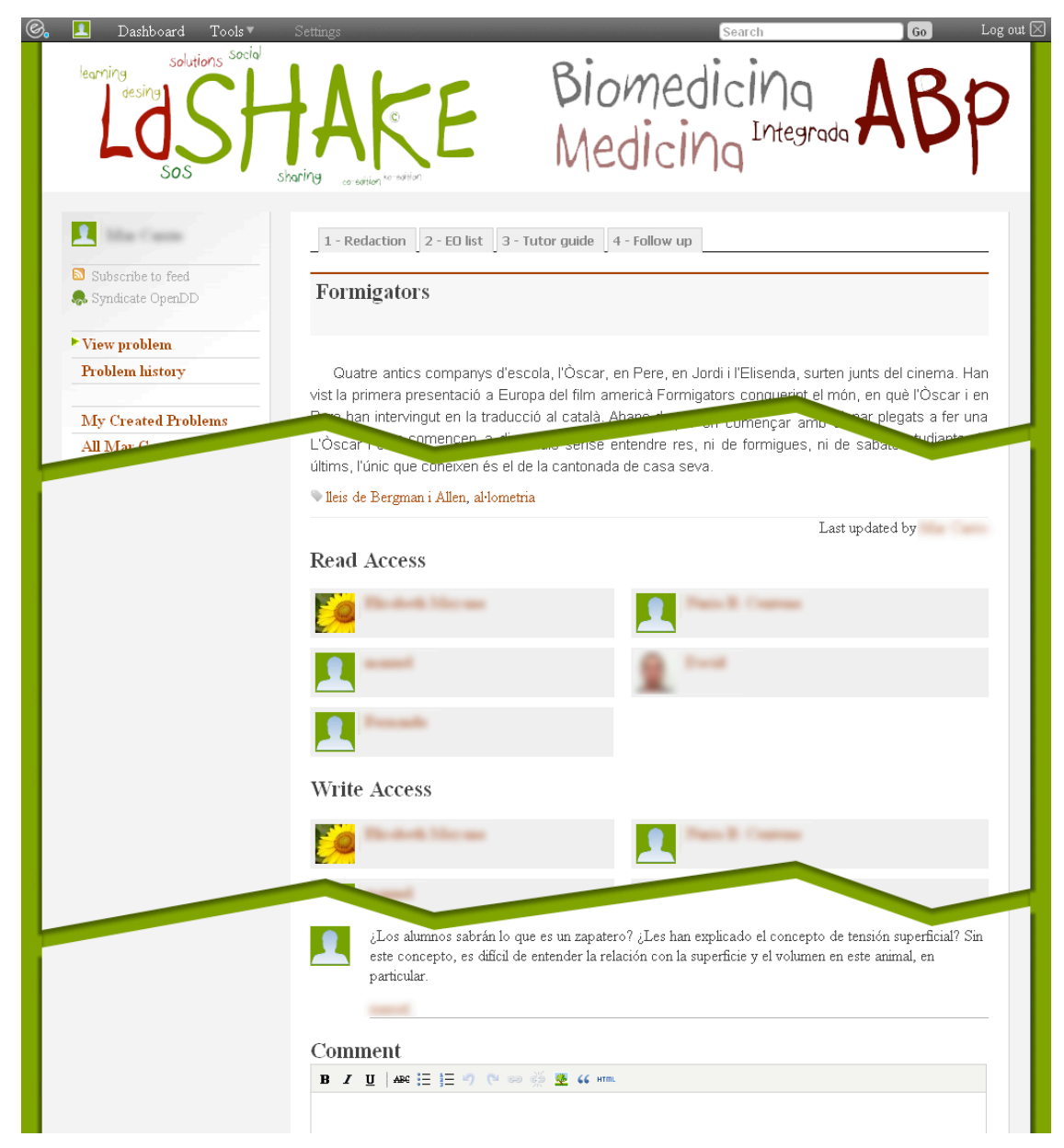

Fig. 3. LdShake applied to the PBL-based Integrated Biomedicine course

The process followed to elaborate the problems started with a face-to-face meeting with all of the teachers, where the learning objectives were defined together and directly written in LdShake.

Afterwards, the course coordinator added a problem scenario and a tutor's guide draft. Teachers involved in the same course had reading and editing rights to propose changes and additions to the problems. Teachers involved in a different BMI course had only reading rights.

Fig. 3 shows a piece of a real learning design example authored with LdShake (in Catalan) by the teachers of the BMI integrated course. The example is a problem structured according to the PBL methodology. The starter of the design was the coordinator of the BMI course and entitled it as "Formigators". The aim of the coordinator for this problem was to present a scenario setting out essential Biology questions, namely: Why we, human beings, have such sizes and shapes? What is the relationship between the size of an animal, its shape, its biological functions and its habitat? What limitations can appear in the changes that animals experiment along their evolution? The disciplines involved in the understanding of these questions are Physics, Zoology, Antropology and Ecology. Therefore, the coordinator shared the Formigators problem with four teachers, each of them expert in one of these disciplines, so that they could participate in the authoring of the problem. They carefully co-edit the scenario presented in the problem, which finally narrated how a group of friends (Biology students), after watching a film in the cinema about giant insects, discusses about the feasibility of the giant insects' sizes. The teachers meticulously selected the sentences used in the friends' discussion so that important elements of the different disciplines were considered. Moreover, using the commenting support of LdShake, the teachers talked about whether the students already mastered the previous knowledge needed in order to solve the problem. As a consequence of these discussions they adapted the writing of the problem. Furthermore, the teachers also knew that they could update the problem whenever they wanted in LdShake and republish it so that the link to the problem available to the students was automatically updated. So, in case teachers noticed any special difficulty with the problem they always had the possibility of easily adding more information (hints) to the scenario.

Besides the writing of the scenario, the teachers also jointly elaborated the targeted educational objectives and the tutor guide (see Fig. 3). The resulting objectives posed for the problem include that the students had to be able: to describe the relationship between the size of an animal and the size of its parts; 
to identify how the parts of the body change structurally in response to the size changes (concept of allometry); to understand how the proportion surface/volume change with the size; to differentiate the physiological processes that depend on the surface from those that depend on the volume; to describe the effect of the body size in the body temperature regulation and relate it with the concepts of ectothermy and endothermy; to describe the relationship between the size of an animal and its habitat using the physical laws of Bergman and Allen to test hypothesis of whether giant insects can exist; and to debate about the different known animal cooperation models. Other teachers of the Integrated Biomedicine courses could read the problem and follow its elaboration for awareness purposes and so as to consider any overlapping with the other problems they were elaborating.

Before using LdShake, most of the teachers involved in the courses participated in a one-hour training session. In this short session, the main features of LdShake were presented. At the end of the session the teachers agreed on the usefulness of the tool to support the collaborative problem creation for their courses. In particular, they pointed out the value of the tool when compared to alternative solutions. Given their previous (pilot) experience using the e-mail as the communication tool to mediate their collaboration, they appreciated the co-authoring support provided by LdShake as well as the provision of an integrated site where all the problems are available and its elaboration is easily and flexibly followed. When compared to co-editing solutions available online, such as Google Docs, teachers valued the social support of LdShake (sharing with pre-defined groups of teachers, differentiated rights for creator/coeditor/reader, attaching a sequence of comments to each design, etc.) and the fact that LdShake is a devoted tool for the creation of LdS (customized template for problem-based LdS; organization of the LdS into "My created LdS", "LdS I can edit", "All LdS (I can read)"; specific metadata and search/exploration support with tag clouds, etc.).

The actual use of LdShake along the problem elaboration process did assist the course coordinator's task. Two significant debates were generated in LdShake (comments feature) that led to adjust the learning objectives of two problems, and, as a consequence, modifications were introduced in the problem scenario and in the tutor's guide. In a third problem, the comments added to the LdS did not lead to any change in the design, but helped in the problem supervision (tutoring task). In another case where the elaboration of the tutor's guide was divided cooperatively between the team of teachers (without a draft initially provided by the coordinator), the LdS co-authoring support proved to be very useful and the coordinator largely valued the revision history feature of LdShake. The problems were published as ready LdS through unique URL and linked in the Moodle system used by the students. However, teachers and students requested a more printable-friendly visualization, and the coordinator also created PDF documents with the problems.

According to the teachers' opinions collected during unstructured interviews in 2010, the potential use of LdShake in their context is higher than the actual usage observed. They said that they were still in the process of familiarizing themselves with Web 2.0 tools and the new collaborative dynamics generated with their colleagues. In addition, they indicated that in some cases the problems written by the coordinator did not really need to be improved, especially in the cases where the problems were reused from the previous pilot experiences. All in all, the teachers highlighted the usefulness of LdShake for supporting the sharing of the problems (and associated materials), for obtaining a visualization of the problems elaborated via the tag clouds, and for significantly facilitating the coordination task.

\subsection{Controlled user study}

This section describes the user study that has been carried out in order to complement the conclusions of the previous real case regarding the suitability of LdShake for the sharing and co-edition of learning design solutions. The experimental design of this user study is based on the use of a control system to enable the formal comparison of LdShake with another system that teachers could use to for collaboration purposes. This method is commonly employed for the validation of interactive systems (Cairns \& Cox, 2008; Georgiakakis, Papasalouros, Retalis, Papaspryrou, \& Siassiakos, 2005; Vega-Gorgojo et al., 2010). Thus, educators employed alternatively the experimental and control system to complete a set of predefined representative tasks. Outcome measures are based on the time required to complete the tasks, the success of the tasks completion and users' perceived difficulty. To further evaluate the strengths and limitations of LdShake, both quantitative and qualitative data sources have been combined. Qualitative data enable further interpretation of the quantitative results. Mixing both types of data is commonly used to better comprehend the analysis of studies involving human processes, which are inherently complex (Morse, 2003).

In this study, Moodle was selected as the control system as it is a well-known tool available in a large number of educational institutions. Though its main purpose is supporting learning processes, many teachers use Moodle to share resources or to collaborate in educational innovation projects (Dodero et al., 
2007; Koper \& Tattersall, 2004). Both LdShake (see Fig. 4) and Moodle (see Fig. 5) were populated each with the same 20 learning design solutions from the Phoebe Repository (Phoebe, 2010). These designs were translated into Spanish. Half of these designs were available with reading rights and the other half with editing access rights. In Moodle this was achieved by adding designs as resources (that can be only read) and as wikis (that other users can edit). Attached to each design, a forum module was configured so that posting comments to the designs was possible. Though Moodle was configured so that its features were as similar as possible to LdShake's facilities, the possibility of sharing designs with specific users in the system was not achieved. Table 1 shows the five tasks proposed to the educators. Tasks 1 and 5 represent the main use cases related to sharing designs with different access rights. Tasks 2 and 3 are devoted to active collaboration use cases, namely editing the design or providing comments. Task 4 is focused on making available, outside the system, the (co-)edited designs. Table 1 also summarizes the main steps that educators should follow in each platform in order to perform the tasks.

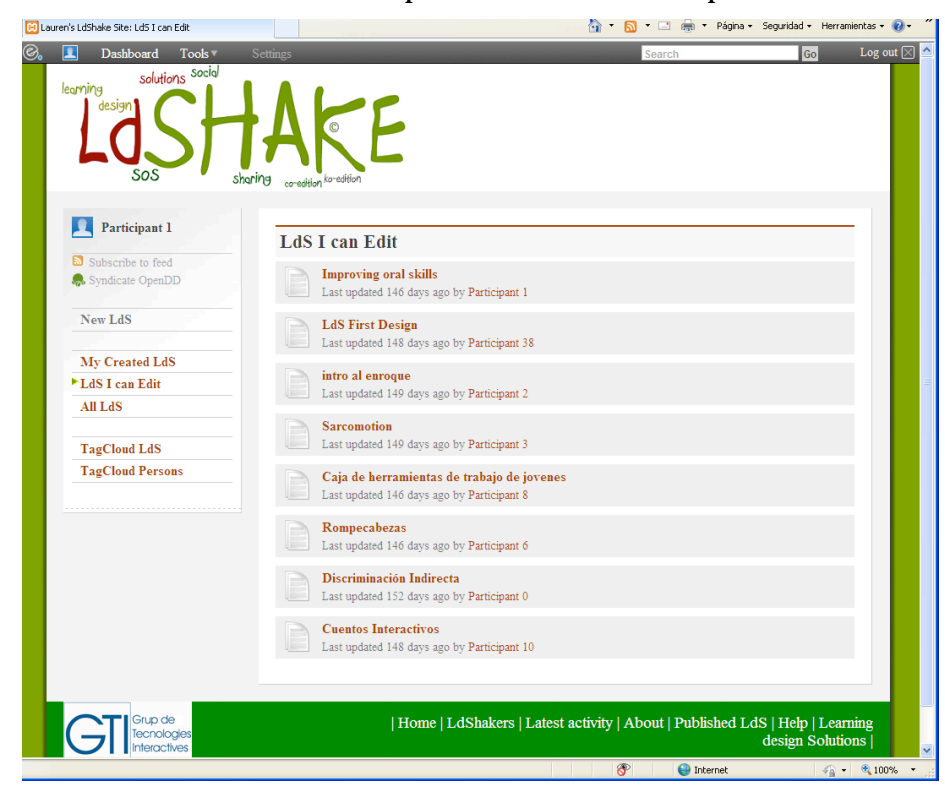

Fig. 4. LdShake as used in the study

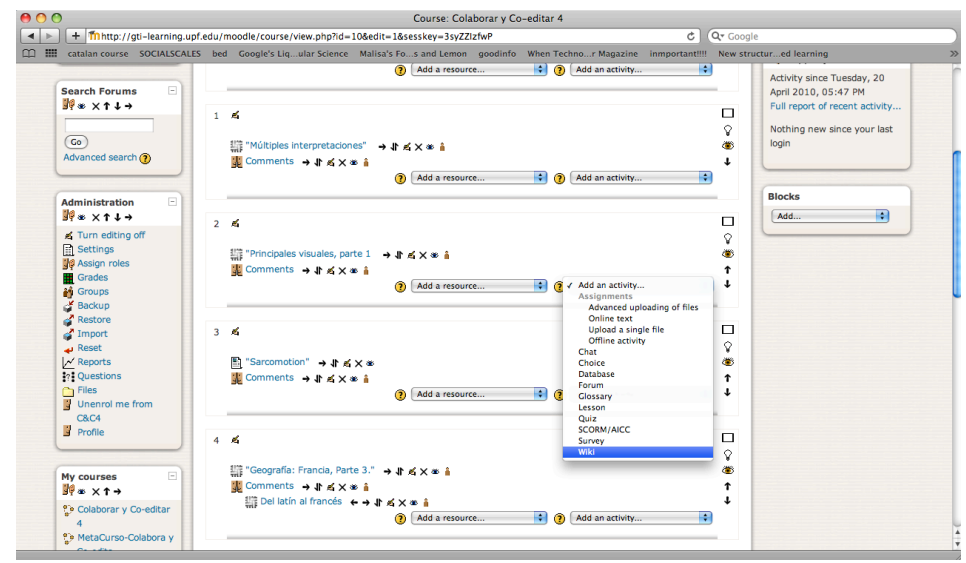

Fig. 5. Moodle as used in the study

Table 1

Tasks and their completion steps in LdShake vs. Moodle (X randomly differs in the tasks proposed to the participants)

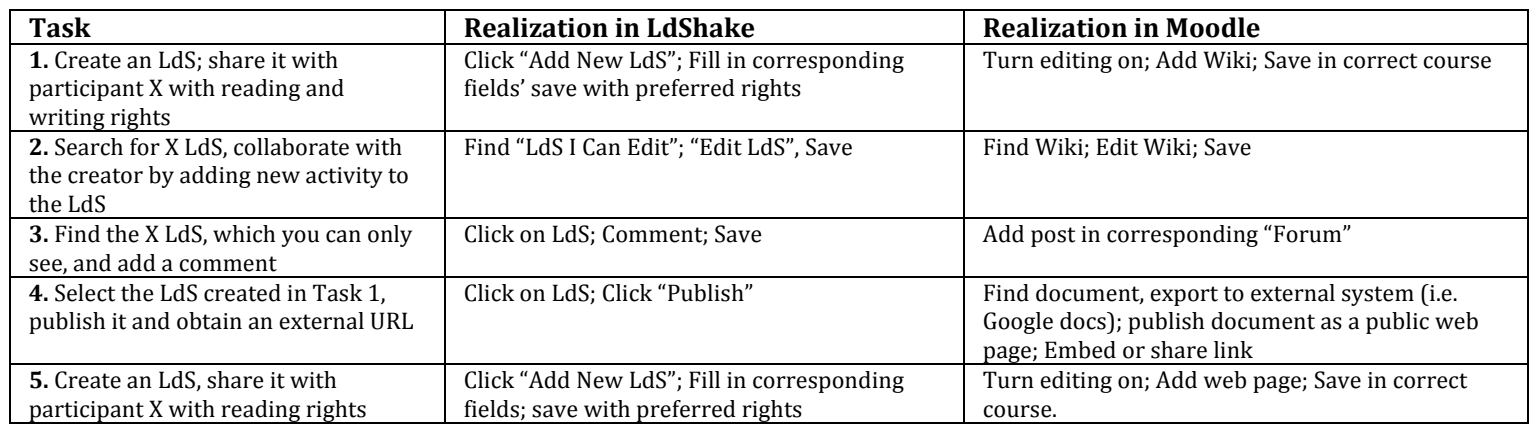


Three different sessions were organized to facilitate the participation of educators. A total of 19 educators volunteered to participate in one of either of the sessions (see Fig. 6). The procedure followed in the study is illustrated in Fig. 7. The first minutes were devoted to request the participants to complete a pre-test about their profile and previous experiences, to introduce the session and to present a brief tutorial of both systems. The tutorials consisted in a 7-minutes aseptic description of both systems, conducted to ensure an equivalence of knowledge of both systems. After that, each participant carried out the five tasks using both systems. The starting system for each participant was randomly determined, as well as the order of the completion of tasks 2, 3, 4 and 5 for each participant. Task 1 was not randomized since it is a prerequisite for task 4. The system and task order randomization was performed to minimize the effect of possible biases. Each participant was provided with a personalized description of the tasks (and their order) as well as a one-page user-guide of each system. When participants considered that they had fulfilled a task, they were asked to complete an intermediate test where they rated the degree of difficulty of the task according to a 5-point Likert scale. After completing the 10 tasks, all participants were requested to respond to a post-test designed to collect global user feedback, and a final discussion with the educators was conducted in order to clarify them any curiosity or question about the tools. Several researchers were present during the sessions to observe and note down any incident and relevant question. Besides, internal system logs (with timestamps) kept track of users' actions with the systems.
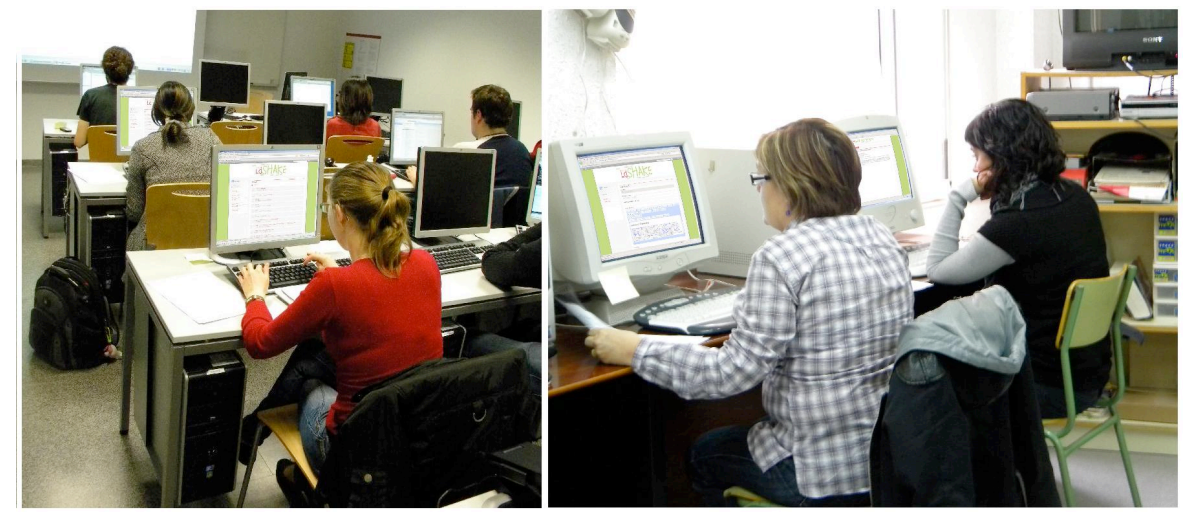

Fig. 6. Photos taken in two of the sessions

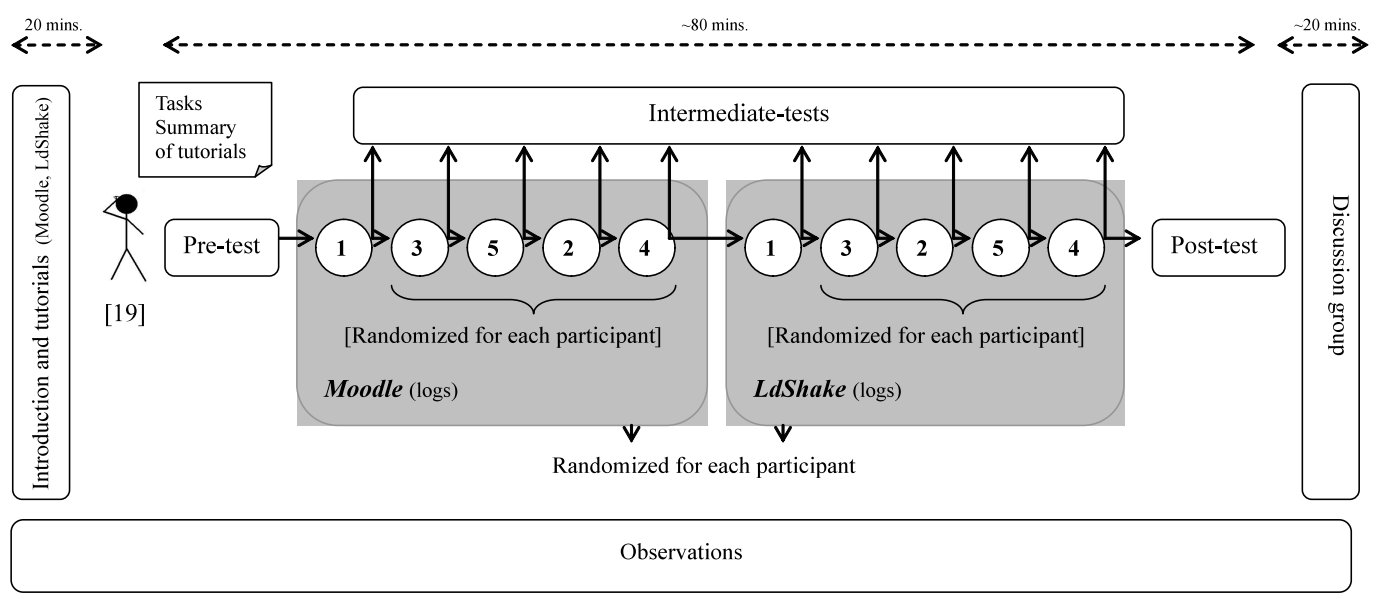

Fig. 7. Schema of the procedure and collected data sources

The analysis of the pre-test showed that the profiles of the educators who participated in the experiment were relatively mixed in terms of age (from 24 to more than 55 years old), sex (35\% men, 65\% women), educational level in which they are involved (42\% K-12 education, 53\% higher education, $5 \%$ adult education), and experience with telematic systems. $70 \%$ of the participants claimed proficiency in the use of specific telematic tools beyond e-mail. They were asked to rate in a 6-point scale (with a score of 1 signifying no experience and a score of 6 signifying expert) their 
level of experience with several telematics tools. The average rates obtained are 4.65 for e-mail (standard deviation of 1.39), 3.95 for on-line forums (deviation of 1.54), 3.85 for on-line collaborative programs (deviation of 1.63), 3.65 for chat tools (deviation of 1.31), 3.55 for social network communities (deviation of 1.80) and 2.22 for micro-blogging tools (deviation of 1.20). This mixture of profiles realistically represents the teaching population and the potential users of the experimental system (which has not been designed for a particular educator profile).

The quantitative analysis of the results includes the use of individual paired-sample t-tests comparing each specific task in LdShake and Moodle and descriptive statistics to quantify users' preferences. The qualitative data collected in the post-tests, observations and discussion groups complement these results.

Paired-samples t-tests were conducted to determine whether there was a significant effect within each individual task (Field, 2009). Fig. 8 summarizes these results. There were not significant differences in the time participants took to complete Tasks 1,2 and $5(p>0.05)$. However, there was a significant effect in how quickly participants completed Tasks 3 and 4 ( $p<$ 0.001), completing the tasks faster in LdShake than in Moodle (see Fig. 8a). Moreover, educators committed more errors in completing the tasks in Moodle than in LdShake $(p<0.05)$ (see Fig. 8b). A significant effect in the perceived level of difficulty (as rated by the educators in the intermediate tests) was found in Tasks 1,3 and $4(p<0.05)$, with participants rating the completion of the tasks in LdShake as less difficult than in Moodle (see Fig. 8c). There was no significant effect in the level of difficulty perceived for Tasks 2 and $5(p>0.05)$.

When the educators were asked in the post-test how easy-to-use was each system (in general), $95 \%$ of the responses were favourable for LdShake (rating LdShake with $\mathrm{M}=1.10 \mathrm{SD}=0.49$ in a scale of 5-very-easy-to-use to 1-very-difficult-to-use). When asked what system the participants found most comfortable to work with, $90 \%$ of the responses were in favor of LdShake $(M=1.15, S D=0.49$ in a scale of 5-very-unconfortable to 1-very-confortable). When asked what system required more time to learn, $75 \%$ of the participants stated Moodle took longer to learn than LdShake. When inquired about LdShake, $95 \%$ of the participants stated it would be a useful tool if they were to create a learning design solution. Furthermore, $85 \%$ of the educators indicated they had sufficiently understood how to create and share LdS with specific rights with other users while $80 \%$ confirmed they had sufficiently understood how to edit and add comments to LdS created by others.
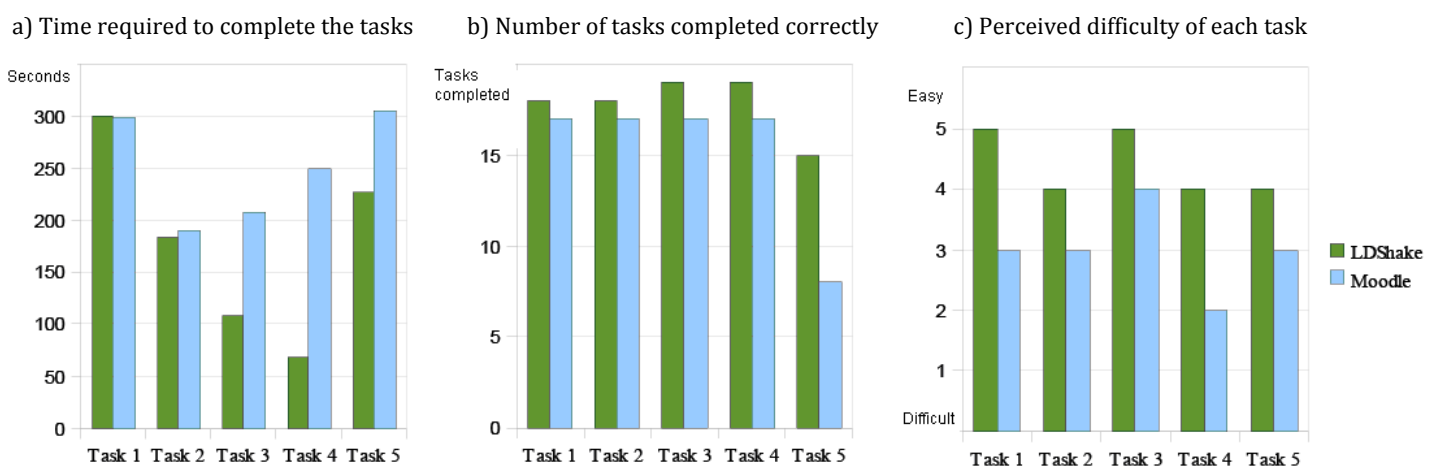

Fig. 8. Results, a) average time (seconds) required to complete each task, b) Number of tasks completed correctly with each system, c) Perceived difficulty of each task (5-very-easy to 1-very-difficult)

The triangulation of these quantitative results with the qualitative comments and observations led to the formulation of the global findings of this user study as summarized in Table 2. The sharing, collaboration and publishing support of LdShake was more effective and usable than the support provided by Moodle; with the most statistically significant features being the support for commenting and publishing LdS. The qualitative positive opinions regarding LdShake sharing support are also particularly noteworthy. The findings are further discussed in the next section together with the main conclusions of the Integrated Biomedicine real application case. 
Table 2

Findings of the user study, triangulating results of the t-tests (tTx), descriptive statistics (DSx), user comments (Cx), direct observations (Ox) and main issues identified in the discussion groups (DGX).

\begin{tabular}{|c|c|}
\hline Findings & Supporting results \\
\hline $\begin{array}{l}\text { Sharing: } \\
\text { LdShake is more effective than } \\
\text { Moodle in the support of sharing } \\
\text { learning design solutions with } \\
\text { different access rights. In } \\
\text { addition, the support of LdShake } \\
\text { is more useful in that it allows } \\
\text { direct sharing with specific } \\
\text { people. LdShake is also perceived } \\
\text { as more intuitive and easier to } \\
\text { use (for sharing purposes). }\end{array}$ & $\begin{array}{l}\text { - Creating a design and sharing it with editing rights (Task 1) is significantly perceived as easier in LdShake than } \\
\text { in Moodle. There is not a significant difference regarding the errors committed or the time required to complete } \\
\text { the tasks, though the results are slightly favourable to LdShake. (tT1) } \\
\text { - Although the difference in the creating a design and sharing it with reading rights (Task 5) is not statistically } \\
\text { significant, some trends are observed from the data in that the completion of the task is more effective with } \\
\text { LdShake (less time and less errors) and easier than with Moodle. (tT5) } \\
\text { - At the end of the experience 85\% of the participants stated they felt confident with their understanding about } \\
\text { how they can create and share LdS with specific rights using LdShake. (DS1) } \\
\text { - Qualitative opinions in the Post-test include: } \\
\text { "The sharing [of LdS] is much more immediate in LdShake..." (C1) } \\
\text { "Just on creation you are given the possibility to choose who else can read and write..." (C2) } \\
\text { "I liked the easy understanding of LdShake as a social network... the route to find the LdS is very easy" (C3) } \\
\text { - Observers noted down: } \\
\text { "Participants sometimes fail in the creation of LdS with specific sharing rights when using Moodle... This is } \\
\text { not a problem in LdShake..." (01) } \\
\text { "Recurrent questions were focused on the fact that when sharing in Moodle, users can only differentiate } \\
\text { between sharing with editing or reading access with all the users in the system, it is not possible to share } \\
\text { with a specific person..." (02) } \\
\text { - The differences regarding the sophistication of the sharing options in LdShake vs. Moodle was the main topic } \\
\text { pointed out in the Discussion groups. Users appreciated the LdShake sharing options as useful. (DG1) }\end{array}$ \\
\hline $\begin{array}{l}\text { Collaboration (co-authoring, } \\
\text { commenting): } \\
\text { LdShake is significantly more } \\
\text { effective than Moodle in the } \\
\text { support of commenting designs } \\
\text { created by others, and seems to } \\
\text { be more effective than Moodle in } \\
\text { the support of co-authoring. }\end{array}$ & $\begin{array}{l}\text { - Searching for a specific design and collaborating with the creator by adding new input (Task 2) seemed to be } \\
\text { more effective in LdShake (less time and less errors) and easier than in Moodle, though the differences are not } \\
\text { statistically significant. (tT2) } \\
\text { - Finding a specific design, which can only be seen (not edited), and adding a comment (Task } 3 \text { ) is statistically } \\
\text { significantly performed in less time, with fewer errors and with a lower degree of perceived difficulty in LdShake } \\
\text { than in Moodle. (tT3) } \\
\text { - At the end of the experience } 80 \% \text { of the participants stated that they felt confident with their understanding } \\
\text { about how they can edit and add comments to LdS created by others using LdShake. (SD2) } \\
\text { - A participant commented in the Post-test: } \\
\text { "... Is it very easy to use and very few steps are necessary to achieve the creation and edition of a design } \\
\text { (which is something to acknowledge)..." (C4) }\end{array}$ \\
\hline $\begin{array}{l}\text { Publishing: } \\
\text { LdShake is significantly more } \\
\text { effective than Moodle in the } \\
\text { support of publishing designs. }\end{array}$ & $\begin{array}{l}\text { - Selecting a created design and publishing it with a external URL (Task 4) is significantly more effective in } \\
\text { LdShake than in Moodle, requiring users less time to complete this task with less errors and a lower level of } \\
\text { perceived difficulty. (tT4) } \\
\text { - In the Discussion groups the participants appreciated the explicit feature of LdShake enabling the on-line } \\
\text { publishing of the created designs. Educators agree that it would be very useful in a scenario where they can keep } \\
\text { making changes in the LdS using LdShake (e.g., if they see that the learning task is very difficult) though it is } \\
\text { being seen by the students in a learning management system where there is a link to the LdS (DG2) }\end{array}$ \\
\hline $\begin{array}{l}\text { Global usefulness and } \\
\text { usability: } \\
\text { Overall, most participants said } \\
\text { they would use LdShake in the } \\
\text { future if they were to collaborate } \\
\text { with other educators in the } \\
\text { creation of joint learning designs. } \\
\text { The majority of the participants } \\
\text { also found more easy-to-use and } \\
\text { to-learn LdShake than Moodle. } \\
\text { It was harder for the participants } \\
\text { to perform the tasks using } \\
\text { Moodle, whose functionalities are } \\
\text { not particularly well valued for } \\
\text { the sharing of designs with } \\
\text { different access rights and for the } \\
\text { organization of the designs. } \\
\text { Integrating LdShake in Moodle } \\
\text { would facilitate the social co- } \\
\text { edition of designs within Moodle. } \\
\text { Besides, participants pointed out } \\
\text { some suggestions for } \\
\text { improvements to LdShake that } \\
\text { include the use of differentiating } \\
\text { icons and a more intuitive } \\
\text { selection of the persons to whom } \\
\text { the designs can be shared. }\end{array}$ & 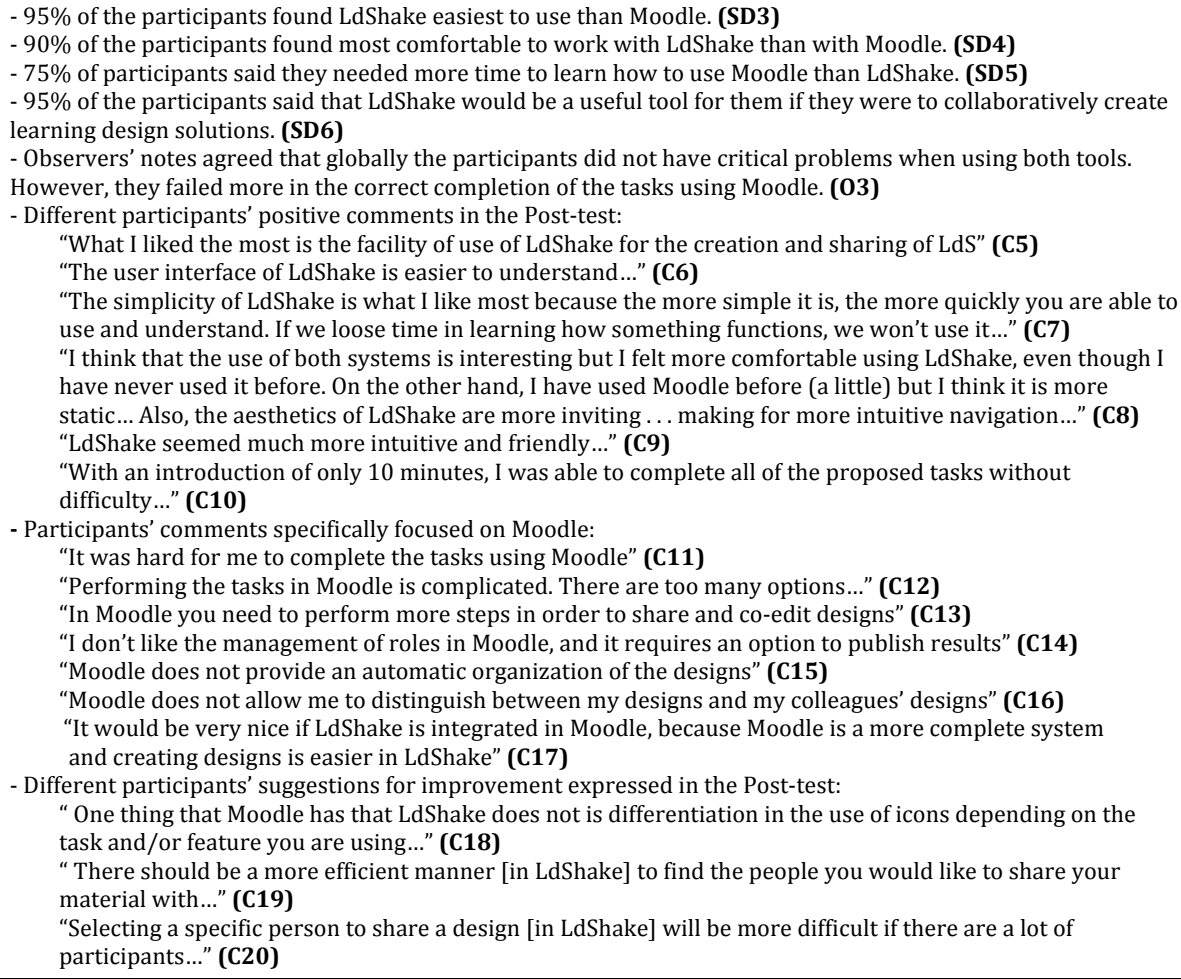 \\
\hline
\end{tabular}




\subsection{Cross-studies discussion}

The cross analysis of the results obtained in the real case and the controlled user study shows that LdShake provides a satisfactory approach addressing the two challenges of facilitating the sharing of learning design solutions and of supporting the cooperation between educators in the coedition of designs in small close communities.

The social network approach of LdShake appeared to be one of its successful features for sharing support. The integrated structure provided by the LdS acting as social objects shared (with read or write access rights) by teams of teachers within the LdShake community, and the organization of the LdS into classifications that consider the access rights, the user-generated tags and the persons that created the LdS were considered more appropriate by the teachers of the Integrated Biomedical courses than the facilities provided by the e-mail or Google Docs (see section 3.1). The user study also shows that LdShake is more effective than Moodle regarding the sharing support (tT1, tT5 - see Table 2). Besides, in contrast to Moodle, LdShake enables the sharing of designs with specific people and not only with the complete community of users (users registered in the system) (C2, 01, 02, DG1). Educators participating in the user study also said that the social network organization assisted them in the searching of LdS (C3).

Another successful feature of LdShake is its commenting support associated to each LdS. The discussion thread of comments facilitated by LdShake was recognized by the teachers of the Integrated Biomedicine course as very useful when compared to Google Docs and was significantly used in the case of three LdS, whose descriptions or implementations were adjusted as a result of the generated debates. The user study proved that LdShake is statistically significantly more effective than Moodle in the support of commenting designs created by others (tT3).

The strength of the co-edition support provided by LdShake relies on its ease of use and the customizable characteristic of the LdS. In the Integrated Biomedicine courses, LdShake was configured so that any newly created LdS was automatically pre-formatted, providing a template for problem-based designs. This facility cannot be achieved with generalist editors such as Google Docs. Besides, the coordinator of the BMI courses valued the revision history feature as useful since it reports teachers' editions to the problems. In addition, the user study shows a trend indicating that the co-edition support of LdShake is easier to use than the support provided by Moodle (tT2, C4).

Publishing the LdS, to be directly linked from other systems, was seen as a very convenient feature by both the teachers of the BMI courses and the educators participating in the user study (DG2). The explicit availability of this feature in LdShake makes publishing the designs created in this tool statistically significantly more effective than publishing the designs created using Moodle (tT4).

The teachers of the BMI course and the participants of the user study recognized the potential of LdShake for supporting the collaboration of teachers in the co-creation of designs. The BMI teachers highlighted that LdShake largely facilitated the coordination task. Most participants in the user study would like to use LdShake in the future (DS6), valued the ease of use of LdShake when compared with Moodle (DS3, DS4, DS5), and stated that they felt confident with their understanding (after the two-hours experiment) about how to use LdShake (DS1, DS2). On the contrary, participants found Moodle harder to use in the completion of the proposed tasks and pointed out a set of drawbacks of this system for the sharing and co-edition of learning design solutions (C11-C17).

On the other hand, according to the two experiences, the usefulness and usability of LdShake could be improved. BMI teachers requested a more printable-friendly visualization of the designs and a PDF export option. The use of icons to differentiate the diverse types of LdS and the redesign of the "selection of person to share an LdS" menu were the main suggestions of the educators participating in the user study (C18-C20).

\section{Conclusions and future work}

LdShake is a social network oriented tool that provides an integrated environment for the sharing and co-edition of learning design solutions by teams of teachers. Among its distinctive characteristics it is important to highlight that the support provided by LdShake is oriented towards teamwork within institutions or transversal thematic teamwork across institutions, and not oriented towards fully open collaboration. LdShake goes beyond existing co-edition approaches 
since it is structured as a social network system specifically designed for the teacher-centred creation and sharing of learning design solutions.

With LdShake, it is the creator (or originator) of a learning design solution (LdS) who decides who forms the team of teachers (LdShakers) working on its edition and whether other registered teachers in the system will be able to see the LdS and post comments to it. In this way, LdShake's aim is beyond the sharing of design ideas and fosters the co-creation of design solutions. The LdS format is generic but it can be particularized, in different instances of LdShake, according to the needs of specific educational institutions or communities of teachers.

LdShake has been used in a real case where groups of teachers with different backgrounds are required to work on the design of Problem-Based Learning solutions. For this case, a particularization of LdShake was instantiated so that it provided pre-structured designs according to the PBL methodology. The resulting designs are used in a course where students are expected to integrate the knowledge and skills developed in previous courses. Besides, a controlled user study has been conducted. The user study compares LdShake with Moodle, configured to enable the creation and sharing of designs. Participants carried out five tasks with each system, being the tasks representative of the sharing and co-edition use cases. The combined results of both studies show that the social structure, and the commenting, co-edition and publishing features of LdShake provide a useful, effective and usable approach for facilitating teachers' teamwork. The formal comparison has been conducted with Moodle, however qualitative comparison comments regarding the e-mail and Google Docs have also emerged from the real case study. Other studies comparing LdShake with related systems, such as those pointed out in the introduction, could be carried out. Nevertheless, any of these systems is completely comparable with LdShake, as some of them are more oriented to large-scale open sharing and others are only devoted to edition. In this sense, it seems to have more interest to study the use of LdShake in real scenarios, such as the Integrated Biomedicine courses, where educational communities can value the usefulness and usability of the sharing and co-edition integrated features of LdShake within their context.

LdShake is currently being used in two additional contexts. The first setting is a socio-educative cooperative where educators and monitors are in charge of creating materials for their own colleagues' training. The second context involves the use of LdShake by a community of teachers of 20 high schools distributed among the region of Catalonia, Spain. The community, officially recognized by the government of Catalonia, is devoted to create and share educational materials that promote the situated learning of Biology topics. In both cases, LdShake has been customized according to the needs of each context.

Current work also includes the revision of the identified usability issues, the development of IMS LD templates that can serve as the basis of LdS and the integration of different authoring tools so that LdShake allows educators a choice of formats for the design solutions. Furthermore, exploring the use of incentives or rewards, such as crediting the individual contributions or using a popularity classification, to encourage teachers to actively collaborate in this type of system seems to be a relevant future research line.

\section{Acknowledgements}

This research has been partially funded by the Spanish Ministry of Science and Innovation Learn3 project (TIN2008-05163/TSI) and a Generalitat de Catalunya project for Enhancing Teaching Quality (2008MQD 00069). The authors want also to thank other members of the GTI research group for their support and ideas, especially to Mar Pérez-Sanagustín, Ernesto Arroyo, Patricia Santos and Javier Melero.

\section{References}

Abelson, H. (2008). The creation of OpenCourseWare at MIT. Journal Science Education and Technology, 17(2), 164-174.

AUTC. Learning designs, products of the AUTC project on ICT-based learning designs. Retrieved March 2011, from http://www.learningdesigns.uow.edu.au

Barrows, H. S. (2002). Is it truly possible to have such a thing as dPBL? Distance Education, 23(1), 119-122.

Cairns, P., \& Cox, A. L. (2008). Research methods for human-computer interaction. Cambridge: Cambridge University Press. 
Calvo, R.A., O'Rourke, S.T, Jones, J., Yacef, K., \& Reimann, P., (2011). Collaborative writing support tools on the Cloud. IEEE Transactions on Learning Technologies, 4(1), 88-97.

Carrió, M., Larramona, P., Baños, J. E., \& Pérez, J. (in press). The effectiveness of the hybrid problem-based learning approach in the teaching of biology: a comparison with lecture-based learning. Journal of Biological Education, (RJBE-2010-0013).

Cifuentes, L., Sharp, A., Bulu, S., Benz, M., \& Stough, L. M. (2009). Developing a web 2.0-based system with userauthored content for community use and teacher education. Educational Technology Research and Development, 58(4), 377-398.

Conole, G., Culver, J., Williams, P., Cross, S., Clark, P., \& Brasher, A. (2008). Cloudworks: Social networking for learning designs. Ascilite Conference, Melbourne, Australia. 187-196.

Davis, H. C., Carr, L., Hey, J. M. N., Howard, Y., Millard, D., Morris, D., et al. (2010). Bootstrapping a culture of sharing to facilitate open educational resources. IEEE Transactions on Learning Technologies, 3(2), 96109.

Dodero, G., Ratcheva, D., Stefanova, E., Miranowicz, M., Vertan, C., \& Musankoviene, V. (2007). The virtual training center: A support tool for teachers community. Balkan Conference in Informatics, Sofia, Bulgaria. 349-362.

Elferink, R., Griffiths, D., \& Veenendaa, E. (2006). The OpenDock project: Putting in place the infrastructure for sharing learning activities. International Workshop in Learning Networks for Lifelong Competence Development, TENCompetence Conference, Sofia, Bulgaria.

Field, A. P. (2009). Discovering statistics using SPSS. Los Angeles, CA: SAGE Publications.

Georgiakakis, P., Papasalouros, A., Retalis, S., Papaspryrou, N., \& Siassiakos, K. (2005). Evaluating the usability of web-based learning management systems. Themes in Education, 6(1), 45-59.

GLOW. Scotland intranet for education. Retrieved 03/01, 2011, from http://www.ltscotland.org.uk/glowscotland/index.asp

González-Barbone, V., \& Anido-Rifón, L. (2010). From SCORM to Common Cartridge: A step forward. Computers \& Education, 51(1), 88-102.

Hernández-Leo, D., Harrer, A., Dodero, J. M., Asensio-Pérez, J. I., \& Burgos, D. (2007). A framework for the conceptualization of approaches to "create-by-reuse" of learning design solutions. Journal of Universal Computer Science, 13(7), 991-1001.

Knorr-Cetina, K. (1997). Sociality with objects: Social relations in postsocial knowledge societies. Theory, Culture \& Society, 14(4), 1-30.

Koper, R., \& Olivier, B. (2004). Representing the Learning Design of Units of Learning. Educational Technology \& Society, 7(3), 97-111.

Koper, R., \& Tattersall, C. (2004). New directions for lifelong learning using network technologies. British Journal of Educational Technology, 35(6), 689-700.

LAMS. LAMS, central repository of LAMS sequences. Retrieved 03/01, 2011, from http://www.lamscommunity.org/lamscentral//

Lloret, T., \& Mir, A. (2006). What has happened during the 1st year of the implementation of the EHEA in some degrees? outcomes in the UPF in terms of academic performance, satisfaction and the learning process. Red U. Revista De Docencia Universitaria, 1(1), http://revistas.um.es/red u/article/view/3311.

Lockyer, L., Bennett, S., Agostinho, S., \& Harper, B. (2008). Handbook of research on learning design and learning objects. New York: Information Science Reference.

Lowry, P.B., \& Nunamaker, J.F. (2003). Using Internet-based, distributed collaborative writing tools to improve coordination and group awareness in writing teams. IEEE Transactions on Professional Communication, 46(4), 277-297.

McAndrew, P., Santos, A., Lane, A., Godwin, S., Okada, A., Wilson, T., et al. (2008). OpenLearn research report. Milton Keynes, England: The Open University.

Morse, J. M. (2003). Principles of mixed methods and multimethod research design. In A. Tashakkori., \& C. M. Teddlie (Eds.), Handbook of mixed methods in social \& behavioural research (pp. 189-208). Thousand Oaks, CA, USA: Sage publications, Inc.

Neumann, S., Klebl, M., Griffiths, D., Hernández-Leo, D., Fuente, L., Hummel, H., et al. (2010). Report of the results of an IMS learning design expert workshop. International Journal of Emerging Technologies in Learning, 5(1), 58-72.

Neuwirth, C. M., Kaufer, D. S., Chandhok, R., \& Morris, J. H. (1990). Issues in the design of computer support for co-authoring and commenting. ACM Conference on Computer-Supported Cooperative Work, Los Angeles, CA, USA. 183-195.

Phoebe. (2011). Pedagogic planer. Retrieved 03/01, 2011, from http://www.phoebe.ox.ac.uk/

RIN. (2008). To share or not to share: Publication and quality assurance of research data outputs Report Commissioned by the Research Information Network (RIN). Retrieved 03/01, 2011, from http://www.rin.ac.uk/

Sarasa, A., Canabal, J. M., \& Sacristán, J. C. (2009). Agrega: A distributed repository network of standardized learning objects. 10th International Work-Conference on Artificial Neural Networks, Salamanca, Spain. 466-474.

Sharma, M. (2008). Elgg social networking. Olton, Birmingham: Packt Publishing.

Strobel, J., Jonassen, D., \& Ionas, I.G. (2008). The evolution of a collaborative authoring system for non-linear hypertext: A design-based research study. Computers \& Education, 51(1), 67-85. 
Vega-Gorgojo, G., Bote-Lorenzo, M. L., Asensio-Pérez, J. I., Gómez-Sánchez, E., Dimitriadis, Y., \& Jorrín-Abellán, I. M. (2010). Semantic search of tools for collaborative learning with the ontoolsearch system. Computers \& Education, 54(4), 835-848.

Wichmann, A., Engler, J., \& Hoppe, H. U. (2010). Sharing educational scenario designs in practitioner communities. 9th International Conference of the Learning Sciences, Chicago, IL, USA. 750-757. 